\title{
Thresholding Based Method for Rainy Cloud Detection with NOAA/AVHRR Data by Means of Jacobi Itteration Method
}

\author{
Kohei Arai ${ }^{1}$ \\ Graduate School of Science and Engineering \\ Saga University \\ Saga City, Japan
}

\begin{abstract}
Thresholding based method for rainy cloud detection with NOAA/AVHRR data by means of Jacobi iteration method is proposed. Attempts of the proposed method are made through comparisons to truth data which are provided by Japanese Meteorological Agency: JMA which is derived from radar data. Although the experimental results show not so good regressive performance, new trials give some knowledge and are informative. Therefore, the proposed method suggests for creation of new method for rainfall area detection with visible and thermal infrared imagery data.
\end{abstract}

Keywords-Jacobi itteration method; Multi-Variiate Regressive Analysis; AVHRR; Rainfall area detection; Rain Radar

\section{INTRODUCTION}

Rainfall area detection with satellite based visible and thermal infrared sensor data is tough issue because the visible and thermal infrared sensor data represent just cloud surface reflectance and temperature. In general, the rainy clouds which cause rainfall can be divided into two kinds, nimbostratus and cumulonimbus. The reflectance and the temperature at the top of the cumulonimbus are relatively high and extremely cold, respectively because the height of the cumulonimbus is quite high. On the other hand, the reflectance and the temperature of the nimbostratus are comparatively low and relatively warm, respectively because the height of the nimbostratus is comparatively low. Meanwhile, no rainy cloud types show very similar characteristics in terms of cloud top reflectance and temperature. Therefore, it is extremely difficult to discriminate between rain and no rain clouds.

There are 10 types of clouds which include four types of cumulus, cumulonimbus, stratus, stratocumulus in the lower cloud, three types of nimbostratus high-rise clouds and high cumulus clouds in the middle clouds, in the high-rise clouds three types of cirrus, cirrocumulus, and cirrostratus. Moreover, these clouds are overlapped sometime. Therefore, it is tough to discriminate rainy clouds by using only reflectance and temperature at the top of the clouds.

Microwave radiometer data represent cloud liquid in rainy cloud. Therefore, some methods for detecting rainy clouds with microwave radiometer data have been proposed already [1]-[9]. On the other hand, limb sounding data also represent some extent of rainy clouds information. Therefore, some methods for rainy cloud detection based on limb sounding data have also been proposed so far [10]-[16].

The rainy cloud detection method proposed here is based on thresholding of visible and thermal infrared radiometer data by means of Jacobi iteration method. The proposed method is to be compared to the multiple linear regressive analyses by only using visible and thermal infrared data observed from space. In the method, Probability Density Function: PDF of the visible and thermal infrared data are calculated. Then the PDF is approximated with the best fit ideal normal distribution. After that, the visible and thermal infrared data are binarized (0 denotes no rain, and 1 means rain) with the most appropriate threshold determined by means of Jacobi iteration method.

The proposed method is described followed by experiments. The experimental results are validated with the posterior created weather maps by using rainfall radar data and the other meteorological data in the following section followed by conclusion with some discussions.

\section{PROPOSED METHOD}

\section{A. Discrimination of Cloud Types}

Within 10 types of clouds, cumulonimbus and nimbostratus clouds are major concern because I intend to discriminate between rainy clouds and the clouds without rainfall. The cumulonimbus clouds are situated in the lower layer of the atmosphere while the nimbostratus clouds are situated in the middle layer of the atmosphere. Therefore, relatively low cloud top temperature and comparatively low cloud top reflectance of clouds have to be found with visible and thermal infrared radiometer data. By using visible and thermal infrared data, appropriate threshold which allows discriminate nimbostratus / cumulonimbus and the other clouds has to be determined.

\section{B. Jacobi Iteration Method}

The proposed method uses Jacobi iteration method. The Jacobi iteration method is expressed as follows,

$$
\begin{aligned}
& g_{k}=g_{k-1}+\alpha_{k} F_{k}^{\prime} \\
& \alpha_{k}=\frac{1}{2}
\end{aligned}
$$




$$
\begin{aligned}
& F_{k}= \\
& \frac{1}{\sqrt{2 \pi \sigma_{S 1}^{2}}} \exp \left(\frac{-\left(g_{k-1}-m_{S 1}\right)^{2}}{2 \sigma_{S 1}^{2}}\right)+\frac{1}{\sqrt{2 \pi \sigma_{S 2}^{2}}} \exp \left(\frac{-\left(g_{k-1}-m_{S 2}\right)^{2}}{2 \sigma_{S 2}^{2}}\right)
\end{aligned}
$$

where $k$ denotes iteration number while $F_{k}$ denotes summation of the PDF functions of the approximated normal distribution of $S_{i}$ (i=1 denotes rainy cloud while $\mathrm{i}=2$ denotes non rainy clouds of visible and thermal infrared radiometer data. Namely, the PDF functions of visible and thermal infrared data are firstly created then the most appropriate approximation normal distribution functions are calculated. After that, cross point between two approximated normal distribution is determined by using Jacobi iteration method. This cross point is used for threshold for discrimination between rainy and non-rainy clouds.

\section{Process Flow}

Fig. 1 shows the process flow of the proposed method for discrimination of rainy and non-rainy clouds with visible and thermal infrared radiometer data.

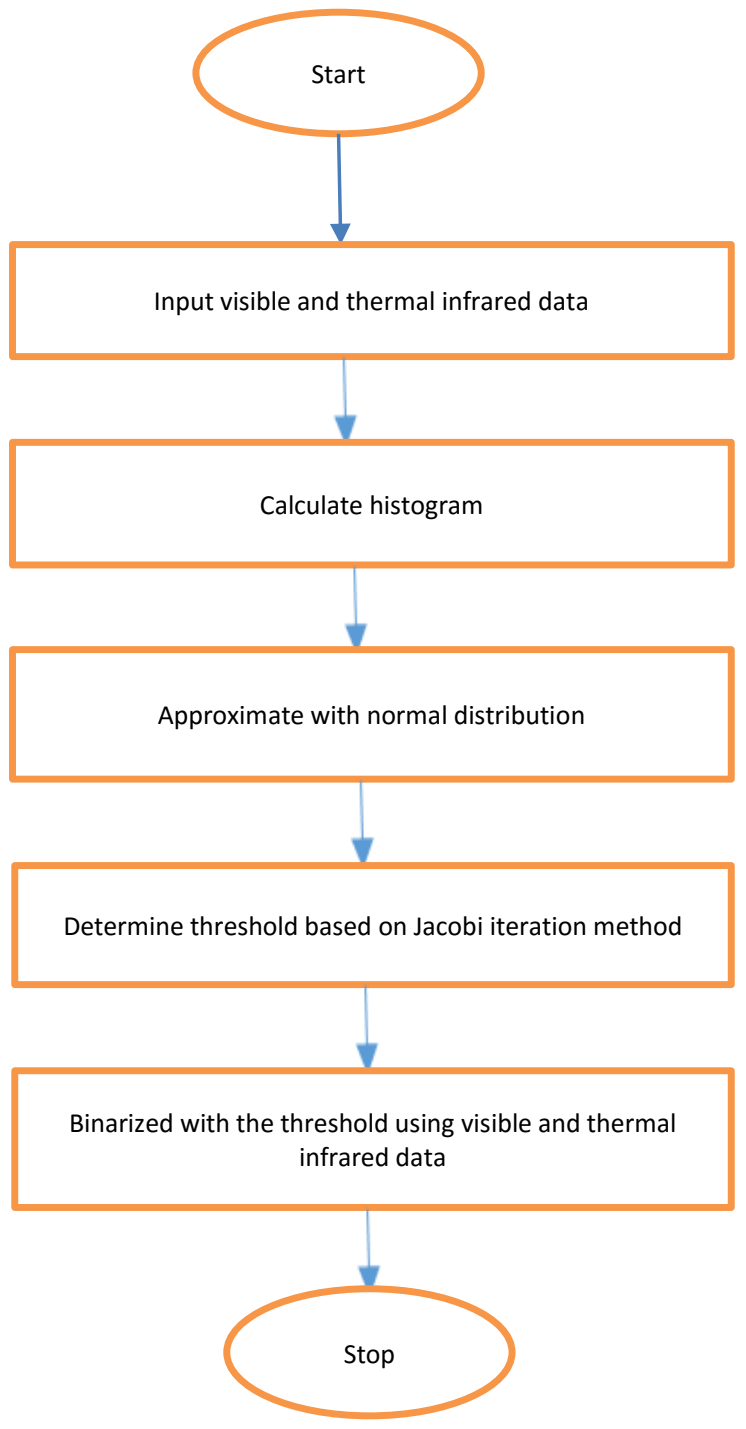

Fig. 1. Process flow of the proposed method for discrimination between rainy and non-rainy clouds with visible and thermal infrared data

\section{EXPERIMENTS}

\section{A. Visible and Thermal Infrared Imagery Data Used}

NOAA/AVHRR (National Oceanic and Atmospheric Administration / Advanced Very High Resolution of Radiometer) of visible and thermal infrared data of Tohoku, Japan which is acquired on February 121997 is used. Visible channel which covers the wavelength ranges from 0.73 to 1.10 $\mu \mathrm{m}$ is used while thermal infrared channel which covers the wavelength ranges from 10.3 to $11.3 \mu \mathrm{m}$ is used.
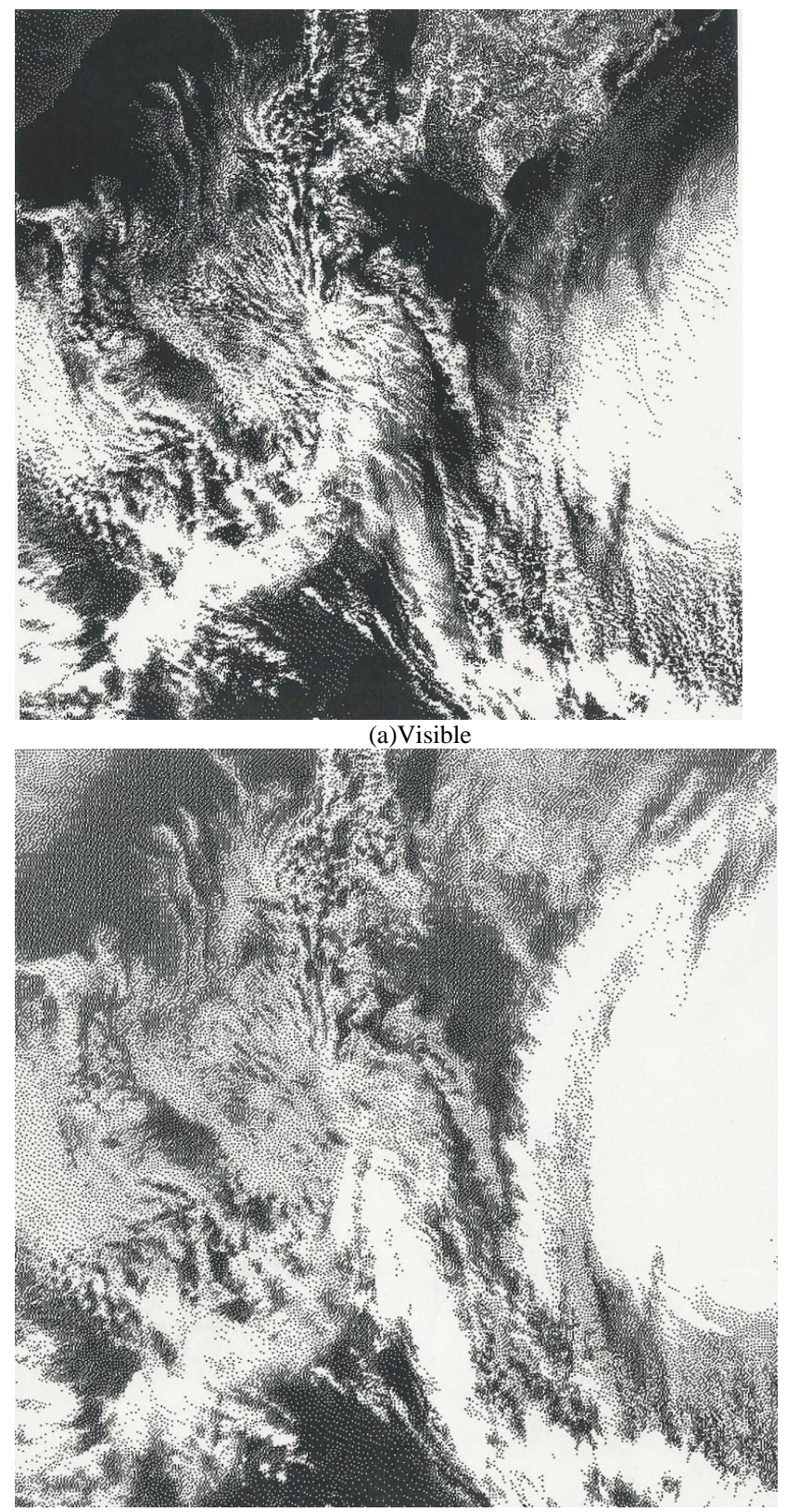

(b)Thermal Infrared

Fig. 2. NOAA/AVHRR of visible and thermal infrared data of Tohoku, Japan which is acquired on February 121997 is used for the experiments

Fig. 2 shows the visible and the thermal infrared imagery data used for the experiments. The images consists of 512 by 512 pixels (the pixel represent $2.2 \mathrm{~km}$ by $2.2 \mathrm{~km}$ ground surface areas). Radiometric resolution of visible channel is $0.1 \%$ of 
albedo while that of thermal infrared channel is 0.2 degree $C$. These data are represented by 8 bits (256 levels) while minimum and maximum physical values correspond to 0 to $35 \%$ for visible channel while $243 \mathrm{~K}$ to $294 \mathrm{~K}$ for thermal infrared channel.

\section{B. Truth Data Used}

As a truth data of rainfall areas, radar data derived rainfall areas which is provided by Japanese Meteorological Agency: JMA is used. Fig. 3 shows the radar data derived rainfall areras of image which consists of $500 \mathrm{~km}$ by $500 \mathrm{~km}$ (the pixel consists $2.6 \mathrm{~km}$ by $2.6 \mathrm{~km}$ ). Black areas show the rainfall areas with 1 to $4 \mathrm{~mm} / \mathrm{hr}$ of rainfall rate while hatched areas shows the rainfall areas with less than $1 \mathrm{~mm} / \mathrm{hr}$ of rainfall rate.

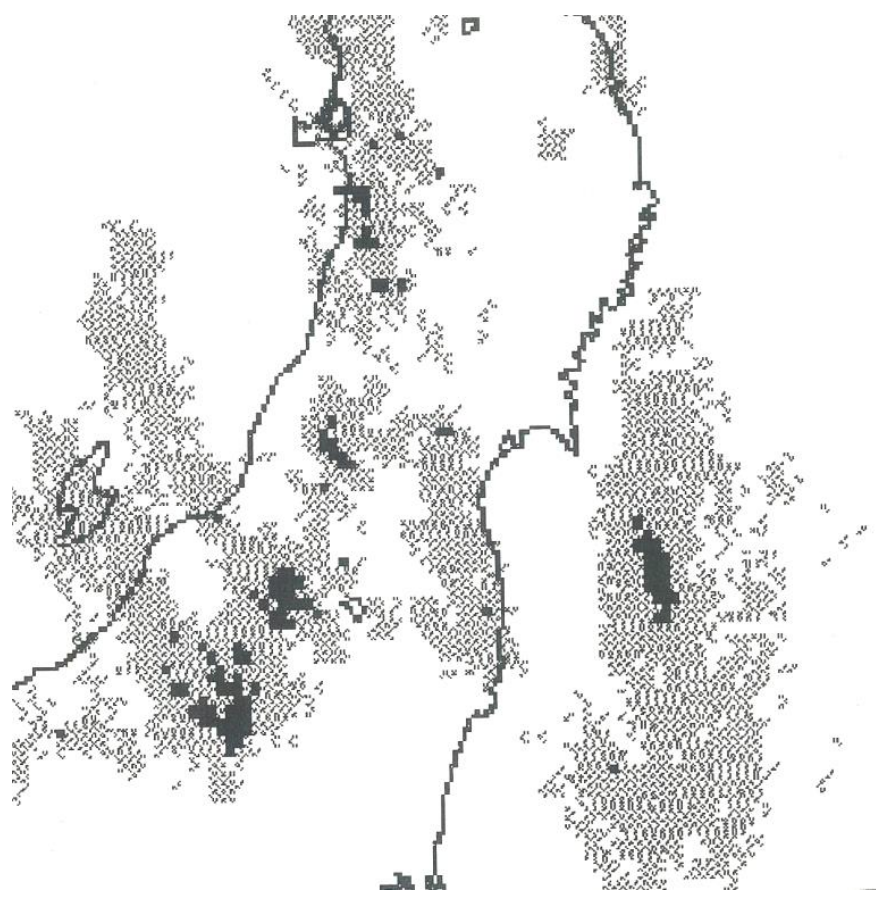

Fig. 3. Radar data derived rainfall areas which is observed at 10:00 in the morning on February 121997

Also, Fig.4 shows the imagery data which are used for multiple linear regressive analysis (Radar data on the right, Visible channel of imagery data in the middle, and Thermal infrared imagery data on the left, respectively) which are acquired on February 121997.

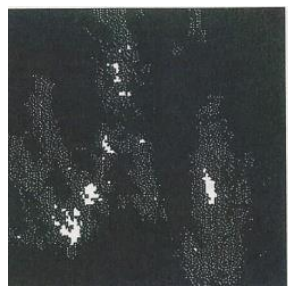

(a)Radar

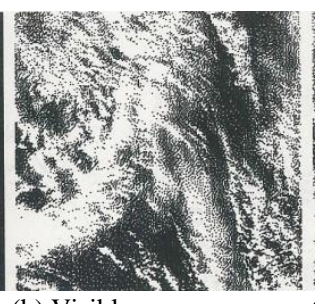

(b) Visible (c) Thermal Infrared

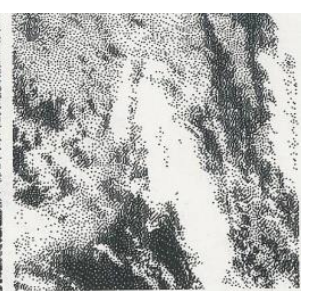

Fig. 4. Imagery data which are used for multiple linear regressive analysis (Radar data on the right, Visible channel of imagery data in the middle, and Thermal infrared imagery data on the left, respectively) which are acquired on February 121997
These visible and thermal infrared imagery data are extracted from the NOAA/AVHRR imagery data. Also, the cloud analysis information image which is acquired at 18:00 on that day provided by JMA and weather map at 12:00, noon on that day is shown in Fig.5 as reference data for rainfall areas. (1) to (4) in Fig.5 (a) denotes cumulus clouds while (5) and (6) areas denote non rainy areas. The eastern portion of Japanese island, in particular, Hokkaido and Tohoku, there are relatively large cloudy areas. Particularly, (1) area shows rainfall areas.
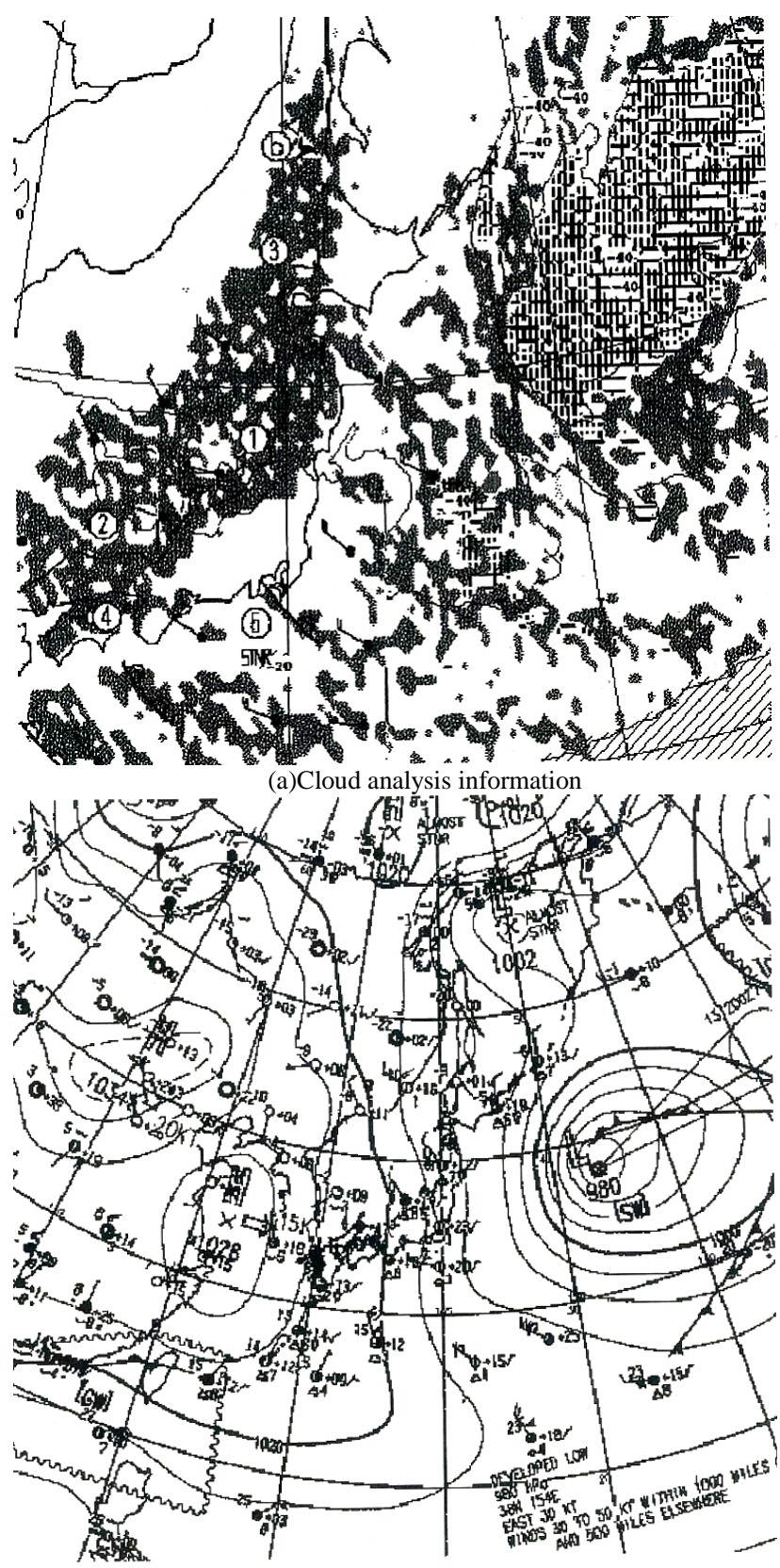

(b)Weather map

Fig. 5. Cloud analysis information image which is acquired at 18:00 on that day and weather map at 12:00, noon on that day are shown in Fig.5 as reference data for rainfall areas 


\section{Experimental Results}

Fig.6 (a) shows histograms of rainy (S1) and non-rainy (S2) cloud areas of visible channel of imagery data and the approximate PDF functions for the histograms for both rainy and non-rainy cloud areas. Meanwhile, Fig.6 (b) shows histograms of rainy (S1) and non-rainy $(\mathrm{S} 2)$ cloud areas of thermal infrared channel of imagery data and the approximate PDF functions for the histograms for both rainy and non-rainy cloud areas. The mean and variance of S1 of the visible channel of data are 168.874 and 877.135 , respectively while those for S2 of visible channel of data are 238.292 and 748.170 , respectively.

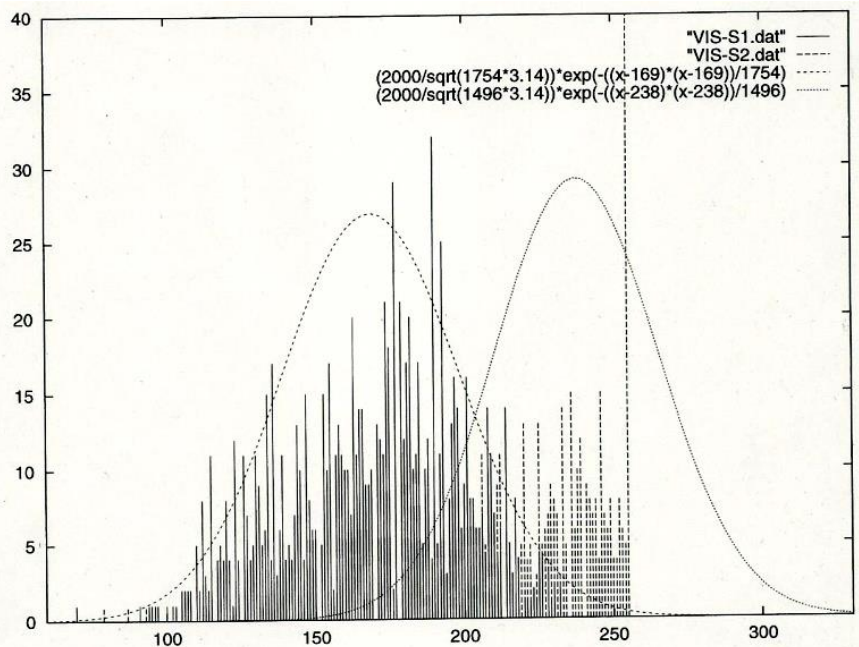

(a)Visible

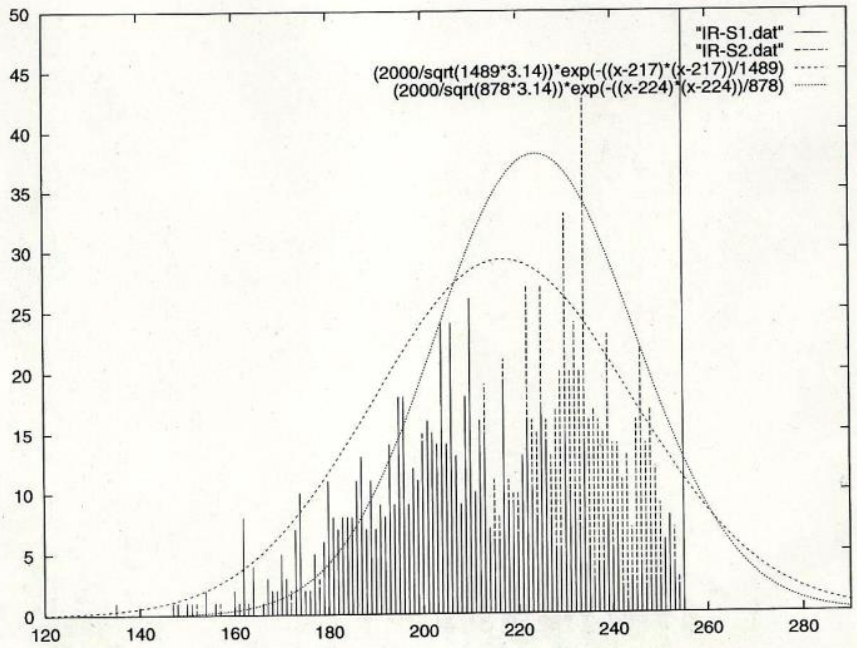

(b)Thermal Infrared

Fig. 6. Histograms of rainy (S1) and non-rainy (S2) cloud areas of therma infrared channel of imagery data and the approximate PDF functions for the histograms for both rainy and non-rainy cloud areas

It is found that histograms of rainy and non-rainy clouds are very close for the thermal channel of data while those are relatively distinguishable for the visible channel of data.

Fig.7 (a) shows the binarized image of the visible channel of data while Fig.7 (b) shows that of the thermal infrared channel of data with the determined thresholds by the Jacobi iteration method, respectively.

\section{Validation of the Proposed Method}

Fig.8 (a) shows raw image of Rainfall radar while Fig.8 (b) shows the rainfall rate extracted image with rain fall radar data. On the other hand, Fig.9 shows the extracted rainfall areas with NOAA/AVHRR of visible and thermal infrared imagery data. White square box in the Fig.9 shows the corresponding area of interest with the rain radar derived rainfall areas.

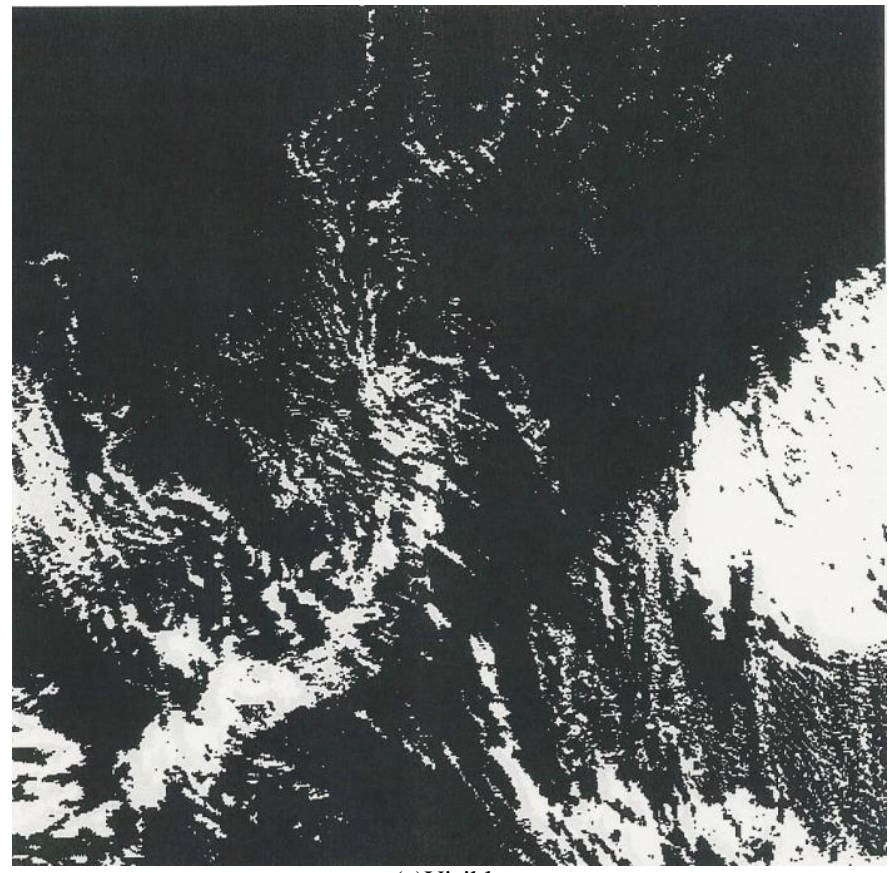

(a)Visible

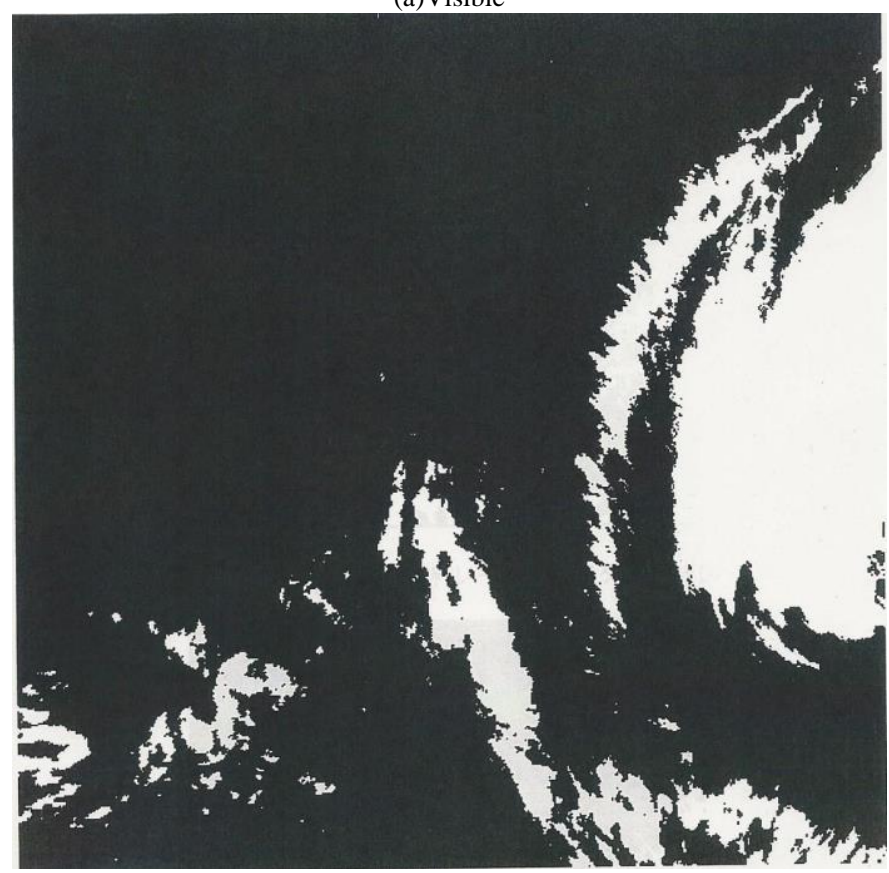

(b)Thermal

Fig. 7. Binarized images of the visible and the thermal infrared channels of data which are acquired on February 121997 
Through comparisons between rainfall radar data derived rainfall rate image and the extracted rainfall areas with NOAA/AVHRR data based on the proposed method, it is found that the extracted rainfall areas with NOAA/AVHRR data based on the proposed method shows relatively heavily rainfall areas. The extracted rainfall areas with NOAA/AVHRR data based on the proposed method is corresponding to the rainfall areas with rainfall rate of 2 to 4 $\mathrm{mm} / \mathrm{hr}$.

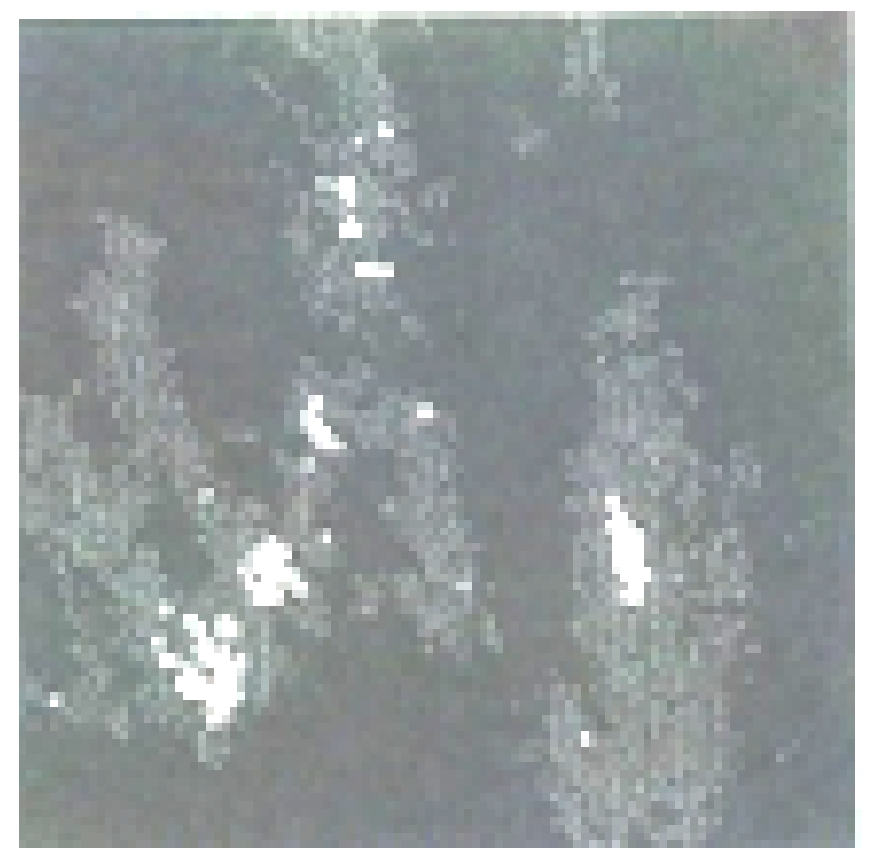

(a)Rainfall radar

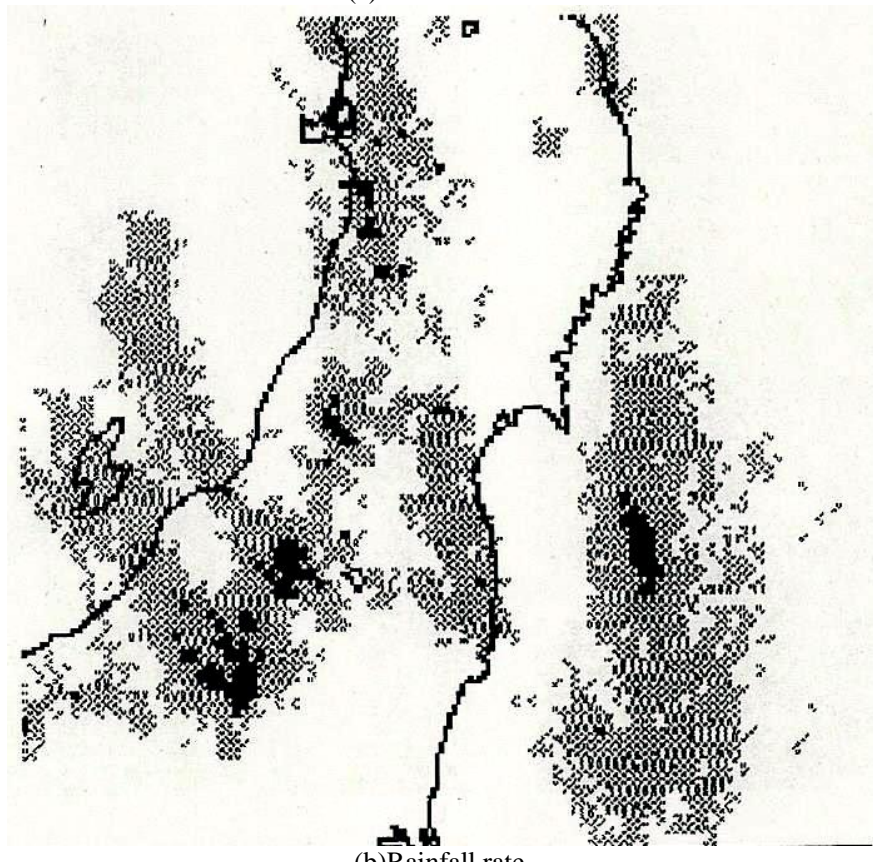

(b)Rainfall rate

Fig. 8. Rainfall radar image and the rainfall rate extracted image with rain fall radar data
Fig.10 (a) shows the binarized image of rainfall radar derived rainfall rate while Fig.10 (b) shows the binarized image of NOAA/AVHRR of visible and thermal infrared data derived rainfall areas based on the proposed method. Both images show marginal coincidence in terms of rainfall areas. Root Mean Square Difference: RMSD between the aforementioned two binarized images is 13.727. Therefore, it is marginal accuracy of rainfall area detection.

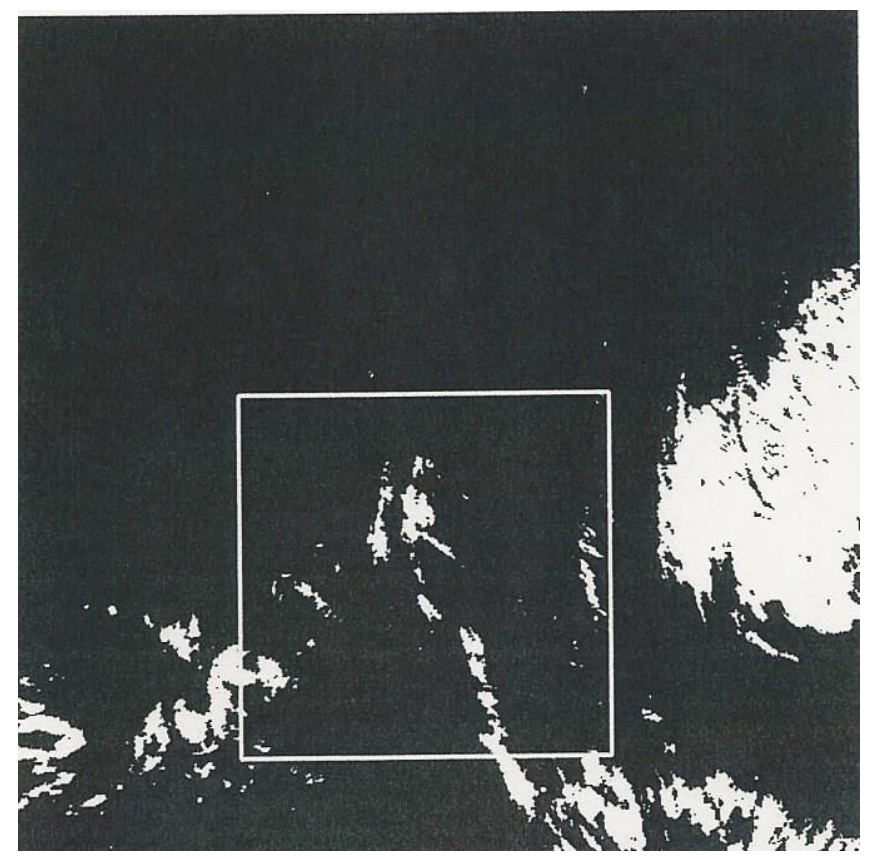

Fig. 9. Extracted rainfall areas with NOAA/AVHRR of visible and thermal infrared imagery data (White square box shows the corresponding area of interest with the rain radar derived rainfall areas)

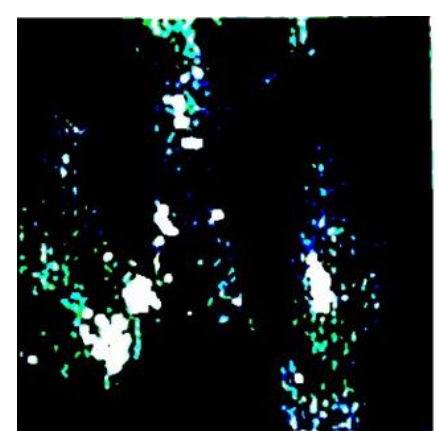

(a)Rain radar

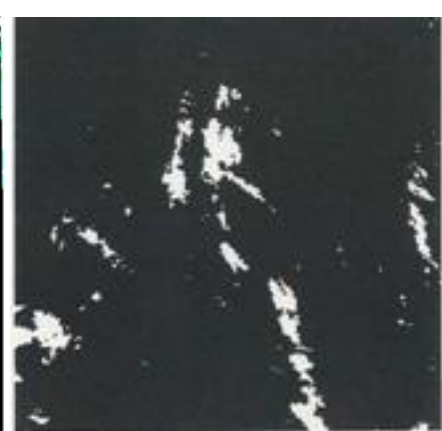

(b) NOAA/AVHRR
Fig. 10. Binarized images of rainfall radar derived rainfall rate and NOAA/AVHRR of visible and thermal infrared data derived rainfall areas based on the proposed method

\section{E. Alternative Method for Rainfall Area Detection}

As described before, there is the alternative method of rainfall area detection, multiple linear regressive analyses: MLRA based method. Namely, rainfall radar data derived rainfall rate is approximated with the NOAA/AVHRR of visible and thermal infrared radiometer data through the MLRA. Fig.11 (a) shows the scatter plots of the rainfall rate 
(AME) and the visible and the thermal infrared channels of NOAA/AVHRR data while Fig.11 (b) shows MLRA equation which is the result from the MLRA expressing the rainfall rate as the functions of the visible channel and the thermal channel of NOAA/AVHRR data.

MLRA equation is expressed in equation (4).

$Z=0.0155 x+0.00941 y+1.731$

where $Z$ denotes rainfall rate while $x$ and $y$ denotes the visible and the thermal infrared channels of NOAA/AVHRR data.

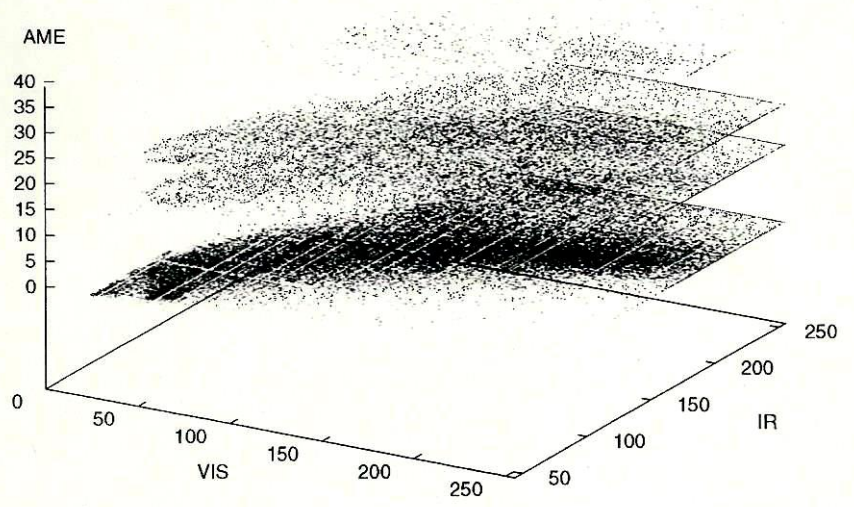

(a)Scatter Plots

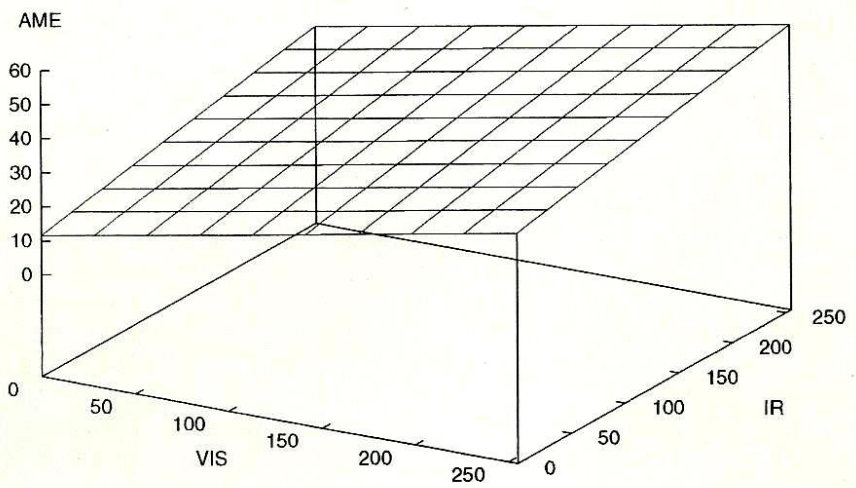

(b)MVRA Equation

Fig. 11. Scatter plots of the rainfall rate (AME) and the visible and the thermal infrared channels of NOAA/AVHRR data and MLRA equation which is the result from the MLRA expressing the rainfall rate as the functions of the visible channel and the thermal channel of NOAA/AVHRR data

The coefficient of determination of the MLRA is 0.020 , and multiple correlation coeffient is 0.142 . Also, degree of freedum corrected coefficient of determination is 0.020 while degree of freedum corrected multiple correlation coefficient is 0.141 . Therefore, not so good correlation is found between rainfall rate and the visible and the thermal infrared channels of NOAA/AVHRR data. Consequently, the proposed method is superior to the MLRA based approach.

\section{CONCLUSION}

Thresholding based method for rainy cloud detection with NOAA/AVHRR data by means of Jacobi iteration method is proposed. Attempts of the proposed method are made through comparisons to truth data which are provided by Japanese Meteorological Agency: JMA which is derived from radar data. Although the experimental results show not so good regressive performance, new trials give some knowledge and are informative. Root Mean Square Difference: RMSD between two binarized images of the rainfall radar derived rainfall rate and the NOAA/AVHRR derived rainfall area detected resultant image is 13.727. Therefore, it is concluded that the proposed method has a marginal accuracy of rainfall area detection. Therefore, the proposed method suggests for creation of new method for rainfall area detection with visible and thermal infrared imagery data.

Through the comparison between the proposed method and the multiple linear regressive analyses, it is concluded that the proposed method is superior to the Multiple Linear Regressive Analysis: MLRA based approach.

Further investigations are required for new additional information such as collocated microwave radiometer data and limb sounding data.

\section{ACKNOWLEDGMENT}

The author would like to thank Mr. Hirokazu Taniguchi of former student of Saga University for his effort to conduct the experiments.

\section{REFERENCES}

[1] Chuang, C. and K. V. Beard, A numerical model for the equilib- rium shape of electrified raindrops, J. Atmos. Sci., 47, 1374- 1389, 1990.

[2] Crewell, S., H. Czekala, U. LShnert, and C. Simmer, MICCY- a 22 channel ground-based microwave radiometer for atmopsh- eric research, submitted to Radio Science, 2000a.

[3] Crewell, S., U. LShnert, A. van Lammeren, and C. Simmer, Cloud remote sensing by combining synergetic sensor information, Phys. Chem. Earth (B), 25, No. 10-12, 1043-1048, 2000 b.

[4] Czekala, H., S. Crewell, A. Hornbostel, A. Schroth, C. Simmer, and A. Thiele, Validation of microwave radiative transfer cal- culations for nonspherical liquid hydrometeors with ground- based measurements, J. Appl. Meteorol., 2000, (submitted for publication).

[5] Czekala, H. and C. Simmer, Microwave radiative transfer with nonspherical precipitating hydrometeors, J. Quant. \$pectros. Radiat. Transfer, 60, 365-374, 1998 .

[6] Fox, N., and A. J. Illingworth, The potential of spaceborne cloud radar for the detection of stratocumulus clouds, J. Appl. Me- teorol., 36, 676$687,1997$.

[7] Gfildner, J. and D. Spiinkuch, Results of year-round remotely sensed integrated water vapour by ground-based microwave radiometry, J. Appl. Meteorol., 38, 981-988, 1999.

[8] Mishchenko, M. I., Calculation of the amplitude matrix for a nonspherical particle in a fixed orientation, Appl. Opt., 39, 1026-1031, 2000.

[9] Solheim, F., J. Godwin, E. R. Westwater, Y. Han, S. Keihm, K. Marsh, and R. Ware, Radiometric profiling of temperature, water vapor and cloud liquid water using various inversion methods, Radio Science, 33, 393-404, 1998.

[10] Ameur, Z., Ameur, S., Adane, A., Sauvageot, H., Bara, K., (2004) Cloud classification using the textural features of Meteosat images. International Journal of Remote Sensing, 25, 21, 4491-4503

[11] Feidas H., Giannakos A., (2010) Identifying precipitating clouds in Greece using multispectral infrared Meteosat Second Generation satellite data. Theor Appl Climatol DOI: 10.1007/s00704-010-0316-5

[12] Haralick, R., Shanmugan, K., Dinstein, I., (1973) Texture features for image classification. Transactions on Systems, Man, and Cybernetics, 3, $6,611-621$ 
[13] Kwon, E., Sohn, B., Schmetz, J., Watts, P., (2010) Intercomparison of height assignment methods for opaque clouds over the tropics. J. Atmos. Sci., 46, 1, 11-19

[14] Strabala, K., Ackerman, S., (1993) Cloud Properties Inferred from 8$12 \mu \mathrm{m}$ Data. J. Appl. Meteor, 33, 212229

[15] Thies, B, Nauss T, Bendix J (2008b) A new technique for detecting precipitation at mid-latitudes during daytime using Meteosat Second Generation SEVIRI. 2008 EUMETSAT Meteorological Satellite Conference, Darmstadt, Germany

[16] Thies, B., Nauss T, Bendix J., (2008a) Discriminating raining from nonraining cloud areas at mid-latitudes using meteosat second generation SEVIRI night-time data. J. Appl. Meteor, 15, 219-230

\section{AUTHORS PROFILE}

Kohei Aarai He received BS, MS and PhD degrees in 1972, 1974 and 1982, respectively. He was with The Institute for Industrial Science and Technology of the University of Tokyo from April 1974 to December 1978 and also was with National Space Development Agency of Japan from
January, 1979 to March, 1990. During from 1985 to 1987, he was with Canada Centre for Remote Sensing as a Post Doctoral Fellow of National Science and Engineering Research Council of Canada. He moved to Saga University as a Professor in Department of Information Science on April 1990 He was a councilor for the Aeronautics and Space related to the Technology Committee of the Ministry of Science and Technology during from 1998 to 2000. He was a councilor of Saga University for 2002 and 2003. He also was an executive councilor for the Remote Sensing Society of Japan for 2003 to 2005. He is an Adjunct Professor of University of Arizona, USA since 1998 $\mathrm{He}$ also is Vice Chairman of the Commission-A of ICSU/COSPAR since 2008. He received Science and Engineering Award of the year 2014 from the minister of the ministry of Science Education of Japan and also received the Bset Paper Award of the year 2012 of IJACSA from Science and Information Organization: SAI. In 2016, he also received Vikram Sarabhai Medal of ICSU/COSPAR and also received 20 awards. He wrote 34 books and published 520 journal papers. He is Editor-in-Chief of International Journal of Advanced Computer Science and Applications as well as International Journal of Intelligent Systsems and Applications. http://teagis.ip.is.sagau.ac.jp/ 